\title{
Effect of Free Fatty Acid Pretreatment to Yield, Composition and Activation Energy in Chemical Synthesis of Fatty Acid Methyl Ester
}

\author{
Nor Saadah binti Mohd Alias', Harumi Veny ${ }^{1, *}$, Fazlena Hamzah ${ }^{1}$, and Noorhaliza Aziz ${ }^{2}$ \\ ${ }^{1}$ Faculty of Chemical Engineering, Universiti Teknologi MARA, 40450 Shah Alam, Selangor, Malaysia \\ ${ }^{2}$ Faculty of Chemical Engineering, Universiti Teknologi MARA, Pasir Gudang Campus, Johor Branch, Johor, Malaysia
}

*Corresponding author:

tel: $+603-55436301$

email: harumi2244@uitm.edu.my

Received: April 2, 2018

Accepted: November 29, 2018

DOI: $10.22146 / \mathrm{ijc} .34492$

\begin{abstract}
Transesterification of waste cooking oil (WCO) for fatty acid methyl ester synthesis using calcium oxide $(\mathrm{CaO})$ as a catalyst with absence and presence of free fatty acid (FFA) pretreatment (untreated and pretreated) prior to reaction have been investigated. The preliminary study was started from theoretical stoichiometric amount molar ratio of methanol to oil. This preliminary experiment showed that indeed, in transesterification with the chemical catalyst the molar ratio of methanol to oil should be exceeding the theoretical stoichiometric molar ratio, due to the fast reversible reaction. The highest FAME content of $81 \%$ was achieved at a temperature of $75^{\circ} \mathrm{C}$ with pretreated FFA. The composition of methyl ester with pretreated FFA was affected by temperature, where increasing temperature leads to increasing of methyl oleate as major methyl ester in the product. The relation of temperature dependence was further studied by Arrhenius law correlation. It is shown that activation energy was affected by pretreatment of fatty acid. The activation energy $\left(E_{a}\right)$ of transesterification with untreated and pretreated free fatty acid were found as $\pm 16 \mathrm{~kJ} / \mathrm{mol}$ and $\pm 68 \mathrm{~kJ} / \mathrm{mol}$, respectively. Unlike untreated FFA, the $E_{a}$ of transesterification with pretreated FFA was within the range of activation energy for transesterification for the base catalyst. This study showed that methyl ester synthesis was best obtained when FFA was pretreated prior to transesterification. In addition, WCO is a potential feedstock for biodiesel production since it is biodegradable, economical, environmentally friendly and abundantly available.
\end{abstract}

Keywords: biodiesel production; fatty acid methyl esters (FAME) composition; activation energy $\left(E_{a}\right)$; waste cooking oil (WCO)

\section{- INTRODUCTION}

These days, biodiesel become more desirable due to its advantages and the fact that it is produced from renewable resources. Biodiesel contributes minimum effect to the environment and greenhouse. Moreover, biodiesel is free from sulfur and carcinogenic benzene, as it contains $99 \%$ lower sulfur oxide, SOx emission as compared to conventional diesel fuel. Other than that, it also has lower exhaust emission as it releases $20 \%$ less carbon monoxide (CO), 50\% less soot, 30\% less hydrocarbon and $40 \%$ less particulate matter [1]. These facts make biodiesel a substantial alternative for petroleum-based diesel.
According to American Society for Testing Materials (ASTM), biodiesel is mono-alkyl esters of long chain fatty acid that derived from renewable feedstock. It can be synthesized from vegetable oils or animal fats via transesterification reaction. In recent years, many researchers have been interested to study on the nonedible oil as feedstock instead of edible oil as the feedstock. This is due to the edible oil may compete with the demand for food and also due to the high cost of the edible oil itself increases the production cost of biodiesel [2]. One alternative to be a potential substitution to the edible oil is waste cooking oil (WCO). WCO is one of the major wastes generated in restaurants and household cooking activities and problems been arises in disposing 
of the WCO. WCO as feedstocks to the biodiesel production, can resolve the problems with disposal of WCO and lower the biodiesel production cost of [3]. Vegetable oils and fats contain monoglycerides, diglycerides, triglycerides, unsaponified lipids and free fatty acid. Vegetable oils cannot be used directly in diesel engines as the engine cannot operate efficiently due to its high viscosity and poor volatile [4]. Therefore, the oils must adapt transesterification reaction with an alcohol to convert triglycerides into fatty acid methyl esters (FAME). By definition, transesterification is the reaction of triacylglycerol from vegetable oil or animal fat with alcohol, usually methanol or ethanol, to produce methyl or ethyl esters which known as biodiesel [5]. The organic group of the triglyceride will exchange with an organic group of alcohol in three serial and reversible steps. The process starts with the conversion of triglyceride to diglyceride, diglyceride into monoglyceride, and lastly, monoglyceride converted into ester and glycerol as a byproduct. Hence, theoretically, three moles of alcohols are needed to react with triglyceride (oil) to produce fatty acid methyl ester and glycerol as a by-product.

Transesterification can be classified into two types which are one-step and two-steps transesterification [6]. The two-step transesterification is for feedstock with a high content of FFA [7]. Generally, vegetable oil contains high FFA value and high acid content. Therefore, the first step which is pre-esterification of the FFA is done to lower the content of the FFA in the oil to below than 1\% using acid catalyst and then followed by the base-catalyzed transesterification of the treated oil in the second step [8]. Oil that contains high FFA cannot be converted directly into FAME because the free fatty acid will be reacted with the alkali catalyst and will result by the adverse effect of soap formation [6]. This condition can lead to the high viscosity of the fuel, emulsification, and gels as byproducts which cause a problem in product separation and contribute to additional cost to the overall process. Nevertheless, if the oil contains FFA less than $2.5 \%$, it can just undergo one step of transesterification process directly to produce FAME [9].

The transesterification reaction can be catalyzed with the addition of acid, base, or enzyme catalyst [10].
These catalysts can be homogeneous or heterogeneous with the reaction mixture. Application of homogeneous catalyst in the production of biodiesel is more extensive as compared to heterogeneous catalyst due to its availability, high reaction rate and shorter process time [11]. However, it always contributes to some major drawbacks such as: require addition separation of products, hard to recover the liquid catalyst, effluent disposal problems, loss of catalyst, and the product require washing process which will generate a high amount of wastewater thus require an extra cost in the process. Recently, the study of transesterification reaction utilizing heterogeneous catalyst has risen to improve the weakness of homogeneous catalyst in the reaction [11].

In this research, heterogeneous catalyst, calcium oxide, $\mathrm{CaO}$ is used as a catalyst in the transesterification of waste cooking oil (WCO) with untreated and treated FFA prior to reaction. The effects of this free fatty acid (FFA) pretreatment at various temperatures and catalyst amount were evaluated to determine the optimum condition towards methyl ester content. The activation energy $\left(E_{a}\right)$ by following the Arrhenius law equation was also examined.

\section{- EXPERIMENTAL SECTION}

\section{Materials}

Waste cooking oil (WCO) was used as feedstock in this research. WCO was obtained from a collection point in Chemical engineering Faculty, UiTM Shah Alam and was a donation from the community (staff). The WCO was from various sources of waste vegetable oils (palm oil, sunflower, corn, etc.) which have been in the mixture prior to transesterification. Methanol was used in the transesterification reaction. Sulfuric acid was used as an acid catalyst in pre-treatment of oil and calcium oxide was used as a solid base catalyst in the transesterification reaction. Potassium hydroxide, toluene, and phenolphthalein indicator were used for titration to determine the acid value $(\mathrm{mgKOH} / \mathrm{g})$ and free fatty acid content (\%FFA) of oil. F.A.M.E Mix GLC-10 was used as a standard for GC analysis of total FAME. 


\section{Equipment}

Electric heater with magnetic stirrer was used to control reaction temperature which was validated with a thermometer. Gas Chromatograph Mass Spectrophotometer (GC-MS) Agilent 6890 GC was used for FAME analysis.

\section{Procedure}

\section{Transesterification with pretreatment of FFA (Pretreated FFA)}

The esterification-transesterification process is the two-step reactions for oil with high FFA content. The esterification reaction was performed in Erlenmeyer flask placed on an electric heater with a magnetic stirrer. The WCO was weighed and placed in the flask and heated to $65{ }^{\circ} \mathrm{C}$. Then, 10:1 molar ratio of methanol to oil and 10 wt.\% of sulfuric acid was added to the reaction flask. During the reaction, the mixture was stirred constantly using a magnetic stirrer for $180 \mathrm{~min}$. After the reaction, the mixture was cooled down, rinsed slowly with the little amount (drops) of cold water, separated in the separatory funnel in a fume hood for overnight and afterward used for transesterification reaction. The amount of FFA in the esterified oil was determined before performing a transesterification reaction. The transesterification reaction was done by heating $20 \mathrm{~g}$ of oil to a selected temperature on the electric heater with a magnetic stirrer. Then, 15:1 molar ratio of methanol and $\mathrm{CaO}$ catalyst are measured according to the selected variation and mixed with the oil. During the reaction, the mixture was stirred constantly using a magnetic stirrer for $180 \mathrm{~min}$. After that, the mixture was cooled down, placed and transferred into a conical centrifuge tube and centrifuged. After separation, three layers can be observed where the bottom layer is the heterogeneous catalyst; the middle layer is the glycerin and excess methanol, while the top layer is ester which is the biodiesel as shown in Fig. 1.

\section{Transesterification without pretreatment of FFA (untreated FFA)}

The transesterification reaction was performed by heating $20 \mathrm{~g}$ of crude WCO to a selected temperature on the electric heater with a magnetic stirrer. Then, 15:1 molar ratio of methanol and $\mathrm{CaO}$ catalyst are measured

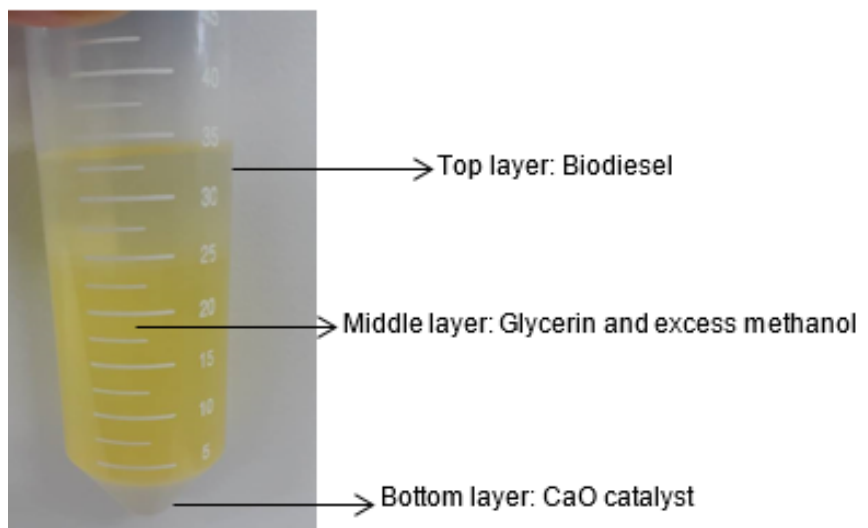

Fig 1. Three layers of the product after centrifugation

according to the selected variation and mixed with the oil. During the reaction, the mixture was stirred constantly using a magnetic stirrer for $180 \mathrm{~min}$. After the reaction, the mixture was cooled down and transferred into a conical centrifuge tube and centrifuged. After separation, three layers can be observed where the bottom layer is the heterogeneous $\mathrm{CaO}$ catalyst; the middle layer is the glycerin and excess methanol, while the top layer is the ester product (FAME). All analysis was conducted in duplicate.

\section{Analysis of FAME content in biodiesel}

The methyl esters mixture was analyzed with Gas Chromatograph Mass Spectrophotometer (GC-MS) Agilent 6890 GC connected to a DB-wax column $(30 \mathrm{~m} \times 0.25 \mathrm{~mm} \mathrm{id} \times 0.25 \mu \mathrm{m})$ with helium as the carrier gas.

The inlet temperature was $250{ }^{\circ} \mathrm{C}$ with oven temperature program as follows: Oven was heated to $50{ }^{\circ} \mathrm{C}$ for $1 \mathrm{~min}$, increase $25^{\circ} \mathrm{C} / \mathrm{min}$ to $200^{\circ} \mathrm{C}$, ramping $3{ }^{\circ} \mathrm{C} / \mathrm{min}$ to $230{ }^{\circ} \mathrm{C}$ and hold for $18 \mathrm{~min}$ [12]. The percentage of FAME content was calculated based on the weight of total methyl ester gained over the weight of the product.

\section{- RESULTS AND DISCUSSION}

\section{Preliminary Study on Equimolar Stoichiometric Amount Ratio of Methanol to Oil}

The preliminary study of transesterification WCO using $\mathrm{CaO}$ was carried out with a stoichiometric molar ratio of methanol to oil 3:1. This is molar ratio theoretically requires for transesterification reaction of oil 


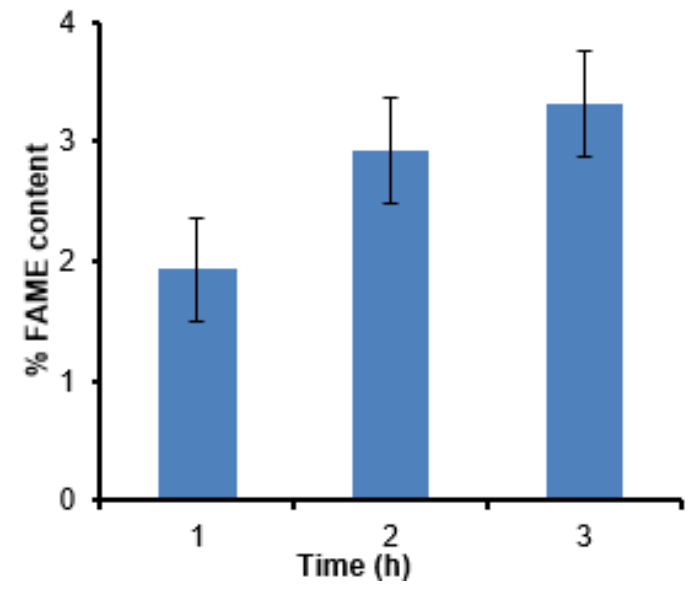

Fig 2. The progress of FAME content in a study on the equimolar amount of methanol to oil

as written in Eq. 1. The $\mathrm{CaO}$ as the catalyst amount was set at $7.5 \mathrm{wt} . \%$ and reaction temperature at $65{ }^{\circ} \mathrm{C}$. The progress of FAME content is shown in Fig. 2. It was observed that the methyl ester content is increasing with increasing of reaction time. However, the FAME content was only $3.3 \%$ which was far below expected theoretical FAME. This is due to the fast reversible reaction where reaction shifts to the reactant. The reaction temperature above the methanol boiling point may also contribute to the loss of methanol during the reaction. This preliminary study was in accordance with most previous studies in transesterification with a chemical catalyst, where high methanol to oil molar ratio was deployed to shift the reversible reaction to the right (product) [14-16]. Hence, the concentration of the methanol was increased for further study of this transesterification reaction.

\section{Effect of Catalyst Loading}

The effect of amount catalyst $(\mathrm{CaO})$ loading on FAME content was performed for both untreated and pretreated FFA prior to transesterifications for a different amount of $\mathrm{CaO}$ at $2.5,5,7.5$, and 10 wt.\% based on oil weight. The reaction temperature was set to $65^{\circ} \mathrm{C}$, with methanol to oil molar ratio (15:1) above the stoichiometric molar ratio. The highest FAME content for untreated and treated FFA are shown in Fig. 3. The FAME content for both reactions increased with the increase of catalyst loading up to $7.5 \mathrm{wt} . \%$. The highest FAME content was achieved at a catalyst loading of $7.5 \mathrm{wt} . \%$ with FAME of

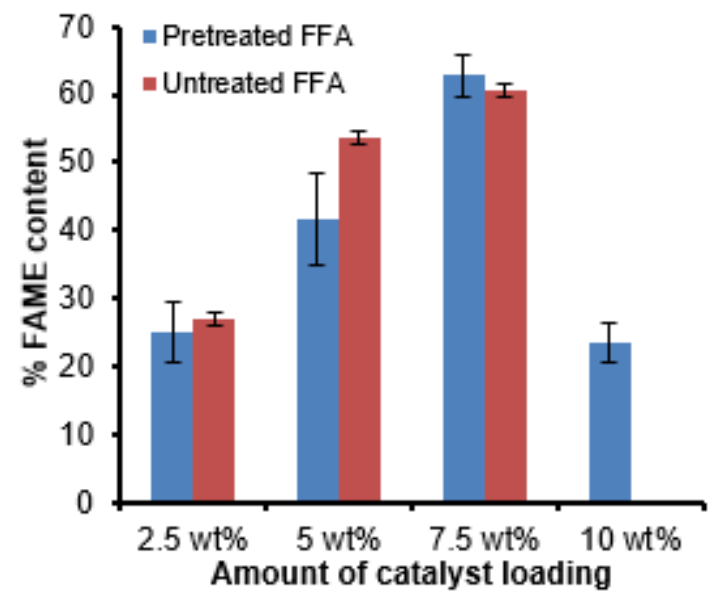

Fig 3. Effect of catalyst $\mathrm{CaO}$ loading

58 and $65 \%$ for untreated and pretreated FFA, respectively. Additions of catalyst above $7.5 \mathrm{wt}$.\% lead to a decrease of FAME content. This is because, when the excess catalyst was used, the reaction mixture becomes more viscous and can lead to poor diffusion of reactants in the system and thus can result in the low conversion of FAME [17].

\section{Effect of Different Reaction Temperatures}

The effect of different reaction temperatures was studied from 45 to $75^{\circ} \mathrm{C}$ for both untreated and pretreated FFA prior to transesterification. The reaction condition was set at methanol to oil molar ratio of 15:1 and catalyst $(\mathrm{CaO})$ loading of $7.5 \mathrm{wt} \%$ The FAME content is depicted in Fig. 4.

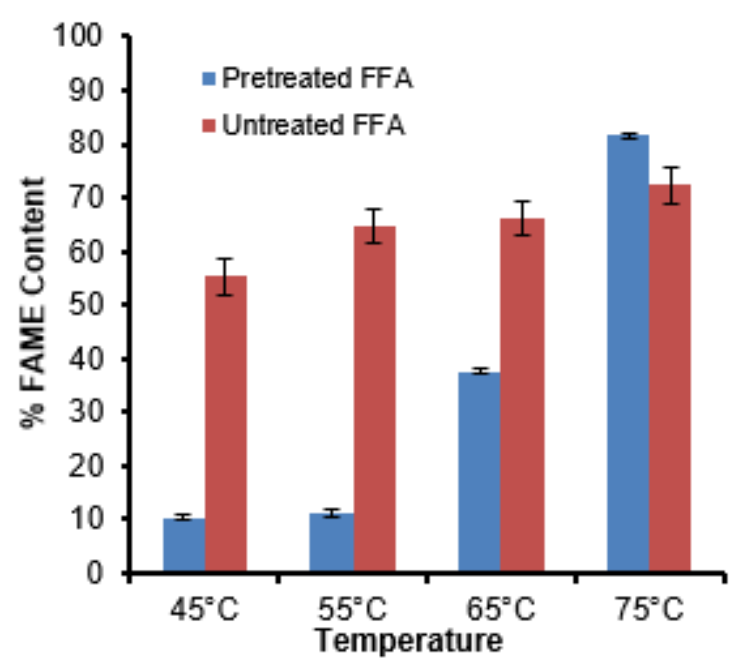

Fig 4. Effect of reaction temperatures on FAME content 
Table 1. FAME composition of pretreated FFA at different temperature

\begin{tabular}{lcccr}
\hline & \multicolumn{4}{c}{ FAME composition (\%) } \\
\cline { 2 - 5 } & $45^{\circ} \mathrm{C}$ & $55{ }^{\circ} \mathrm{C}$ & $65{ }^{\circ} \mathrm{C}$ & $75{ }^{\circ} \mathrm{C}$ \\
\hline Palmitic acid methyl ester (C16:0) & 10.9 & 27.2 & 18.3 & 11.2 \\
Linoleic acid methyl ester (C18:2) & 28.7 & 16.8 & 22.3 & 6.2 \\
Oleic acid methyl ester (C18:1) & 53.6 & 56.1 & 50.8 & 73.2 \\
Stearic acid methyl ester (C18:0) & 6.7 & - & 8.7 & 9.4 \\
\hline
\end{tabular}

The FAME content increased with the increasing temperature up to $75^{\circ} \mathrm{C}$ with the highest FAME of 72 and $81 \%$ for untreated and pretreated FFA, respectively. The increase of temperature up to $75^{\circ} \mathrm{C}$, not only increase the FAME content but also changed the FAME composition as shown in Table 1. Methyl oleate percentage as major fatty acid in FAME from WCO increased with the increase of temperature.

Minimum methyl ester content of $96.5 \%(\mathrm{w} / \mathrm{w})$ is necessary to meet the biodiesel international standard requirement [18-19]. Even though our FAME content for both reactions of pretreated FFA (81\%) and untreated FFA (72\%) were still below the ester content for biodiesel standard, but taking into account that our feedstock was from waste (WCO), these results are potentially promising. Thus, further study is necessary to ensure that biodiesel production from waste should be able to meet the minimum ester content of biodiesel standard.

\section{Temperature Dependence and Activation Energy $\left(E_{a}\right)$ of Transesterification of WCO}

The temperature may affect the reaction up to the certain limit at which the catalyst can speed up the reaction by lowering the activation energy. In order to estimate the activation energy, rate of reaction and its constant must be determined by considering the overall reaction equation.

The overall transesterification of triglyceride with methanol can be simplified as [20]:

$\mathrm{TG}+3 \mathrm{ROH} \leftrightarrow 3 \mathrm{FAME}+\mathrm{GLY}$

TG, ROH, and GLY are Triglyceride, Methanol, and Glycerol respectively. Based on the stoichiometric reversible reaction in Eq. 1, three moles of methanol is needed for equilibrium reaction. However, since methanol was added in excess during the reaction, the transesterification shifted to the right, hence the reaction is assumed irreversible, and methanol was saturated.

The reaction rates can be written as:

rate $=-\frac{\partial[\mathrm{TG}]}{\partial \mathrm{t}}=\mathrm{k} \cdot[\mathrm{TG}]^{\mathrm{x}} \cdot[\mathrm{ROH}]^{\mathrm{y}}$

$\mathrm{k}$ is reaction rate constant, $x$ and $y$ are the orders of reaction. The reaction was zero order respect to methanol and was assumed first order to triglyceride. Hence, the overall irreversible reaction is first order reaction $[16,20]$. The rate of reaction in term of reactant [TG] can be rewritten as:

$\frac{-\partial[\mathrm{TG}]}{\partial[\mathrm{t}]}=\mathrm{k} \cdot[\mathrm{TG}]$

Zhang et al. [21] proposed derivation by taking the integration of Eq. 4 at time $t$ and 0;

$\ln [\mathrm{TG}]_{b}-\ln [\mathrm{TG}]_{\mathrm{t}}=\mathrm{k} \cdot \mathrm{t}$

Since three moles of FAME is produced for each equilibrium reaction, thus;

$[\mathrm{TG}]_{\mathrm{t}}=[\mathrm{TG}]_{0}-\frac{1}{3}[\mathrm{FAME}]$

$[\mathrm{TG}]_{\mathrm{t}}$ and $[\mathrm{TG}]_{0}$ are triglyceride concentration at time $\mathrm{t}$ and 0 , respectively [21].

Using Eq. 4, the rate of reaction constant, $\mathrm{k}$ for temperature from $45^{\circ} \mathrm{C}(318 \mathrm{~K})$ to $75^{\circ} \mathrm{C}(348 \mathrm{~K})$ can be determined as shown in Table 2.

The activation energy of transesterification was estimated for both untreated and pretreated FFA by Arrhenius equation. Arrhenius derived an equation to describe the temperature dependence of simple chemical reactions [22], as follow:

$\mathrm{k}=\mathrm{A} \exp \left(-\frac{\mathrm{E}_{\mathrm{a}}}{\mathrm{RT}}\right)$

After integration, Eq. 6 can be rewritten as:

$\ln \mathrm{k}=\ln \mathrm{A}-\frac{\mathrm{E}_{\mathrm{a}}}{\mathrm{R}}\left(\frac{1}{\mathrm{~T}}\right)$

where, the $\mathrm{k}=$ rate of constant, $\mathrm{A}=$ Frequency factor, 
Table 2. The reaction rate constant for temperature from $45^{\circ} \mathrm{C}(318 \mathrm{~K})$ to $75^{\circ} \mathrm{C}(348 \mathrm{~K})$

\begin{tabular}{lcccc}
\hline \multirow{2}{*}{$\mathrm{T}$} & \multicolumn{2}{c}{$\mathrm{k}\left(\mathrm{sec}^{-1}\right)$} & \multicolumn{2}{c}{$\ln \mathrm{k}\left(\mathrm{sec}^{-1}\right)$} \\
\cline { 2 - 5 } & Untreated FFA & Pretreated FFA & Untreated FFA & Pretreated FFA \\
\hline 318 & $1.062 \times 10^{-6}$ & $2.622 \times 10^{-7}$ & -13.756 & -15.154 \\
328 & $1.765 \times 10^{-6}$ & $2.849 \times 10^{-7}$ & -13.247 & -15.071 \\
338 & $1.830 \times 10^{-6}$ & $9.632 \times 10^{-7}$ & -13.211 & -13.853 \\
348 & $1.923 \times 10^{-6}$ & $2.105 \times 10^{-7}$ & -13.162 & -13.071 \\
\hline
\end{tabular}

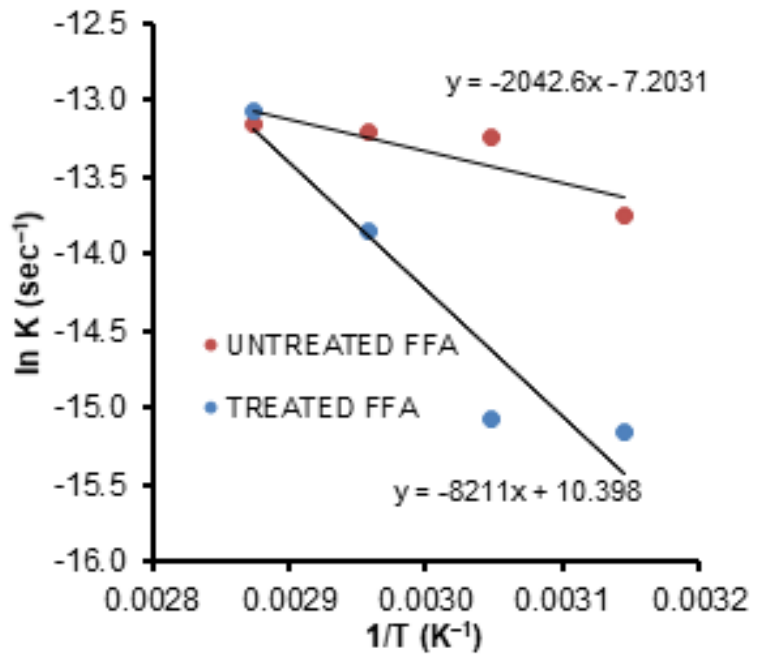

Fig 5. Arrhenius plot of $\ln k$ with $1 / T$ for transesterification of WCO with untreated and pretreated FFA

$\mathrm{E}_{\mathrm{a}}=$ Activation energy $(\mathrm{kJ} / \mathrm{mol}), \mathrm{R}=$ Gas constant: $8.3144 \mathrm{~J} / \mathrm{K} . \mathrm{mol}, \mathrm{T}=$ temperature $(\mathrm{K})$.

The activation energy can be estimated by plotting $\ln \mathrm{k}$ with $1 / \mathrm{T}$ at various temperature, with the slope as $-E_{a} / R$. The plot of $\ln k$ with $1 / T$ for untreated and pretreated of FFA prior to transesterification are shown in Fig. 5.

Good linearity only obtained when plotting $\ln \mathrm{k}$ with $1 / \mathrm{T}$ for pretreated FFA. Further calculation of activation energy $\left(E_{a}\right)$ using Eq. 7, give estimated values of 16 and $68 \mathrm{~kJ} / \mathrm{mol}$ for untreated and pretreated FFA, respectively. Only activation energy from pretreated FFA was within the range of activation energy for transesterification $(33.6-84 \mathrm{~kJ} / \mathrm{mol})$ as stated by Freedman et al. [20].

\section{- CONCLUSION}

In conclusion, a study on the effect of transesterification of waste cooking oil (WCO) with untreated FFA and pre-treated FFA showed that pre- treatment of FFA significantly affect the Fatty acid methyl ester (FAME) production. Transesterification of WCO with pretreated FFA showed high methyl ester content compare to untreated FFA in various studies including the amount of catalyst and reaction temperature. Further observation of pretreated FFA depicted that change in reaction temperatures may change the composition of major fatty acid in FAME. Study of temperature dependence using Arrhenius relation to estimate activation energy also demonstrated that only pretreated FFA has good linearity, with an activation energy $\left(E_{a}\right)$ within the recommended activation energy for transesterification reaction.

\section{- ACKNOWLEDGMENTS}

This study was supported by Lestari Fund 600(RM)/Dana KCM 513 (132/2017).

\section{- REFERENCES}

[1] Zhang, T., Yang, L., Zhu, Z., and Wu, J., 2002, The kinetic study on lipase-catalyzed transesterification of a-cyano-3-phenoxybenzyl alcohol in organic media, J. Mol. Catal. B: Enzym., 18 (4-6), 315-323.

[2] Demirbas, A., Bafail, A., Ahmad, W., and Sheikh, M., 2016, Biodiesel production from non-edible plant oils, Energy Explor. Exploit., 34 (2), 290-318.

[3] Adepoju, T., and Olawale, O., 2014, Acid-catalyzed esterification of waste cooking oil with high FFA for biodiesel production, Chem. Process Eng. Res., 21, 80-86.

[4] Venkateswarulu, T.C., Raviteja, C.V., Prabhaker, K.V., Babu, D.J., Reddy, A.R., Indira, M., and Venkatanarayana, A., 2014, Review on methods of transesterification of oils and fats in bio-diesel formation, Int. J. ChemTech Res., 6 (4), 2568-2576. 
[5] Banković-Ilić, I.B., Stamenković, O.S., and Veljković, V.B., 2012, Biodiesel production from non-edible plant oils, Renewable Sustainable Energy Rev., 16 (6), 3621-3647.

[6] Reshad, A.S., Panjiara, D., Tiwari, P., and Goud, V.V., 2017, Two-step process for production of methyl ester from rubber seed oil using barium hydroxide octahydrate catalyst: Process optimization, J. Cleaner Prod., 142, 3490-3499.

[7] Zamberi, M.M., and Ani, F.N., 2016, Biodiesel production from high FFA rubber seed oil, ARPN $J$. Eng. Appl. Sci., 11 (12), 7782-7787.

[8] Ong, H.R., Khan, M.R., Chowdhury, M.N.K., Yousuf, A., and Cheng, C.K., 2014, Synthesis and characterization of $\mathrm{CuO} / \mathrm{C}$ catalyst for the esterification of free fatty acid in rubber seed oil, Fuel, 120, 195-201.

[9] Ong, H.C., Silitonga, A.S., Masjuki, H.H., Mahlia, T.M.I., Chong, W.T., and Boosroh, M.H., 2013, Production and comparative fuel properties of biodiesel from non-edible oils: Jatropha curcas, Sterculia foetida and Ceiba pentandra, Energy Convers. Manage., 73, 245-255.

[10] Verma, P., and Sharma, M.P., 2016, Comparative analysis of effect of methanol and ethanol on Karanja biodiesel production and its optimisation, Fuel, 180, 164-174.

[11] Mardhiah, H.H., Ong, H.C., Masjuki, H.H., Lim, S., and Lee, H.V., 2017, A review on latest developments and future prospects of heterogeneous catalyst in biodiesel production from non-edible oils, Renewable Sustainable Energy Rev., 67, 1225-1236.

[12] Veny, H., Aroua, M.K., and Sulaiman, N.M.N., 2014, Kinetic study of lipase catalyzed transesterification of jatropha oil in circulated batch packed bed reactor, Chem. Eng. J., 237, 123-130.

[13] Gimbun, J., Ali, S., Karnwal, C.C.S.C., Shah, L.A., Hidayah, N.N., and Nurdin, S., 2013, Biodiesel production from rubber seed oil using activated cement clinker as catalyst, Procedia Eng., 53, 13-19.

[14] Xiao, Y., Gao, L., Xiao, G.M., and Lv, J., Kinetics of the transesterification reaction catalyzed by solid base in a fixed-bed reactor, Energy Fuels, 24 (11), 5829-5833.

[15] Sanjel, N., Gu, J.H., and Oh, S.C., 2014, Transesterification kinetics of waste vegetable oil in supercritical alcohols, Energies, 7, 2095-2106.

[16] Krishnakumar, U., and Sivasubramanian, V., 2017, Kinetic study of preparation of biodiesel from crude rubber seed oil over a modified heterogeneous catalyst, Indian J. Chem. Technol., 24 (4), 430-434.

[17] Maneerung, T., Kawi, S., Dai, Y., and Wang, C.H., 2016, Sustainable biodiesel production via transesterification of waste cooking oil by using $\mathrm{CaO}$ catalysts prepared from chicken manure, Energy Convers. Manage., 123, 487-497.

[18] Barabás, I., and Todoruţ, I.A., 2011, "Biodiesel Quality, Standards and Properties" in BiodieselQuality, Emissions and By-Products, Eds., Montero, G., and Stoytcheva, M., IntechOpen, 3-28.

[19] Prankl, H., Körbitz, W., Mittelbach, M., and Wörgetter, M., 2004, Review on Biodiesel Standardization World-Wide, IEA Bioenergy Task 39, Subtask: Biodiesel.

[20] Freedman, B., Butterfield, R.O., and Pryde, E.H., 1986, Transesterification kinetics of soybean oil 1, J. Am. Oil Chem. Soc., 63 (10), 1375-1380.

[21] Zhang, L., Sheng, B., Xin, Z., Liu, Q., and Sun, S., 2010, Kinetics of transesterification of palm oil and dimethyl carbonate for biodiesel production at the catalysis of heterogeneous base catalyst, Bioresour. Technol., 101 (21), 8144-8150.

[22] Van Boekel, M.A.J.S., 2008, Kinetic modeling of food quality: A critical review, Compr. Rev. Food Sci. Food Saf., 7 (1), 144-158. 